\title{
Multicommunication During a Pandemic: Concepts for Research and Teaching
}

\author{
N. L. Reinsch, Jr. \\ Lubbock Christian University \\ Jeanine W. Turner \\ Georgetown University
}

This study explores factors that influence individual decisions to conduct multiple, simultaneous interactions, that is, to multicommunicate. We present data indicating that: (a) the Covid-19 pandemic increased the frequency of multicommunication; (b) university students multicommunicate in order to achieve instrumental, interpersonal, and identity goals; and (c) while some university students recognize that multicommunication increases the risks of communication failures, others do not. We offer some suggestions for educators who wish to include multicommunication concepts in their courses. We also suggest that business practitioners (and their managers) should consider instrumental, interpersonal, and identity objectives when they choose between face-to-face and electronically mediated interaction.

Keywords: multicommunication, pandemic, media, objectives, instrumental, interpersonal, identity, presence

\section{INTRODUCTION}

During the Spring of 2020, as organizations began to shut down globally, offices closed and work was moved to the home. Prior to the pandemic, research on telework often expressed concerns that workers might spend less time working without the structure of the office environment. However, later research suggested that the many benefits of flexibility and focused concentration actually led to more productive outcomes (Maruyama \& Tietze, 2012; Vanderkam, 2015).

Telework challenges have often involved anxiety around the need for more explicit information sharing routines and the importance of management career development (Maruyama \& Tietze, 2012). However, the pandemic created even more pressures on the home environment as work also moved home (Turner, Wang, \& Reinsch, 2020). All family members were co-located in the home environment where work, school, caregiving, and family life were all taking place (Turner, 2020). Additionally, health concerns and anxiety about the virus itself contributed additional stress (Workplace Mental Health, n.d.). The communication management of an individual's network (e.g., work and customer relationships, extended family, friends, doctors, and other logistical relationships) put extra stress on individual family members as many conversations that had previously taken place outside of the family's home were now conducted from inside the structure (Turner et al., 2020). 
Ten months into the pandemic, research found that people were working more hours than they had when they had worked from offices prior to the pandemic lockdown. In fact, research across 65 countries reported by The Economist suggested that people were averaging longer hours with saved time from commutes being filled with videoconferencing and email (People Are Working, 2020). Multicommunication, engaging in multiple conversations at any one time, had become a necessary means of managing the frontstage, the backstage, and the "intertidal" transitions of existence (Turner et al., 2020).

Multicommunication has been documented in several nations and in a wide variety of workplaces (Reinsch \& Turner, 2019). The primary objective of the current project is to better understand some of the factors that influence individual decisions to multicommunicate. Progress toward that goal should, in turn, help educators to include multicommunication concepts in their courses when appropriate.

Multicommunicating is a learned behavior, a form of multitasking in which each "task" is a communication event that could require the participant to take a speaking turn (Reinsch, Turner, \& Tinsley, 2008). At present, the antecedents and effects of multicommunication are only partially understood (Reinsch \& Turner, 2019).

As the diffusion of the mobile phone has increased over time, the pressures have increased for individuals to remain available, stimulating the need to be able to interact with multiple people at once more frequently (Reinsch \& Turner, 2019). The global pandemic exacerbated this challenge (Turner et al., 2020). Previous research has shown that the pandemic increased the use of media, but has not considered the possibility of increases in multicommunication (Nguyen, Gruber, Marler, Hunsaker, Fuchs, \& Hargittai, in press).

This paper, therefore, contributes to the scholarly literature by reporting data that address three issues: (1) whether the Covid-19 pandemic increased the frequency of multicommunicating behavior among university students; (2) why university students engage in multicommunication; and (3) whether students perceive multicommunicating as entailing risks.

Subsequent sections of the paper include a literature review (with research questions), a description of methods and procedures, a report of results, discussion of the results, and a conclusion. As part of the discussion, we recommend that business instructors consider including multicommunication concepts in their courses.

\section{LITERATURE REVIEW AND RESEARCH QUESTIONS}

The concept of multicommunication was described by Reinsch et al. in 2008 and has been included in a series of subsequent studies. Important contributions have included both theoretical refinement (e.g., Cameron \& Webster, 2011) and measurement procedures (e.g., Stephens, 2012).

According to Reinsch and Turner (2019), multicommunicating provides advantages to practitioners while also exposing them to risks - but neither advantages nor risks have been thoroughly investigated. Nor is it clear whether individuals consider advantages and risks when deciding to multicommunicate. In this paper we explore those issues, guided by the five propositions around which Reinsch and Turner (2019) organized their review.

We collected data in late 2020. At that moment universities were dealing with the consequences of the Covid-19 pandemic. The university at which we collected data had chosen to maintain face-to-face instruction with social distancing, frequent sterilization of classroom surfaces, and provisions for on-line class participation when appropriate. The consequences of these changes were (at that time and still today) not fully understood (Wallace, Burton, Chandler, \& Darby, 2020a). Preliminary studies suggest multiple pandemic-related changes in both understanding and behavior, on the part of both instructors and students

(Wallace, Burton, Chandler, \& Darby, 2020b). These changes may include the practice of multicommunication.

\section{Did the Covid-19 Pandemic Increase the Frequency of Multicommunicating?}

Several of the propositions articulated by Reinsch and Turner (2019) — when considered as a groupsuggest that events such as the Covid-19 pandemic may increase the frequency of multicommunicating. 
Proposition \#2 stated, among other things, that "multicommunicating is facilitated by media with certain characteristics," and that the selection and use of media for a multicommunication episode "will be affected" by a person's "understanding of the relevant media" based on experience (Reinsch \& Turner, 2019, p. 156).

Proposition \#3 included the statement that "the frequency and practice of multicommunicating will be influenced" by perceived norms (Reinsch \& Turner, 2019, p. 157). Norms may, of course, be either explicit or implicit (Stephens \& Davis, 2009).

Proposition \#5 proposed that communication behavior "will continue to evolve, producing continuing change" in various aspects of individual and community life (Reinsch \& Turner, 2019, p. 161). The Covid19 pandemic has certainly altered human behavior, and there are good reasons to think that some of the changes will persist even after the pandemic has come under control (Nguyen et al, in press; Sneader \& Singhal, 2021).

Taken together, propositions \#2 and \#5 suggest that events which encourage people to become more experienced in the use of media will result in more frequent multicommunication. Proposition \#3 suggests that temporary changes in behavior can become permanent when they are taken as signals of changing norms.

More specifically, multicommunication is facilitated by an array of media in which the media being used provide reviewability, rehearsability, and delayability and all, or all but one, provide invisibility. For example, a face-to-face business meeting or class session can limit one's ability to exchange email or texts (Turner \& Foss, 2018). However, a meeting or a class session conducted with video conferencing technology (e.g., Zoom or an equivalent system) greatly reduces those limitations especially for participants who do not have (or do not turn on) a camera attached to their computer. In fact, the chat function built into most video-conferencing systems is designed to allow participants to exchange text messages (e.g., student to student comments) while also interacting audibly with someone else (e.g., a professor). Providing such a feature in a video conferencing system strongly implies a norm that multicommunicating is not only allowed but encouraged.

We believe that the limitations imposed on face-to-face interactions during the pandemic had the effect of requiring people to use electronic technologies (Nguyen et al., in press) and that those technologies allow or encourage multicommunicating. Increased familiarity and experience with those technologies had, we think, the effect of increasing multicommunicating behavior. Unfortunately, we did not have pre-pandemic data that would have allowed us to compare objective measures of pre- and post-pandemic behavior. But we could ask students about their personal perceptions and so we chose to ask the following research question:

\section{Q1: Will students perceive that their multicommunication increased during the pandemic?}

\section{Why Do Students Multicommunicate?}

Reinsch and Turner (2019) propose that multicommunicators are caught between a desire to achieve multiple goals (wanting to participate in multiple, simultaneous interactions) and the limitations of their abilities to receive and process multiple messages. Reinsch and Turner (2019) suggest that persons experience "multicommunicator aspiration stress"-aspiring to participate in more interactions while feeling limited by their personal messaging abilities. Our second (and our third) research question(s) concern aspects of this tension.

Proposition 1-parts $c, d$, and $e$ (Reinsch \& Turner, 2019) — drew on the work of Clark and Delia (1979) who proposed that strategic communication may have objectives of three types: instrumental (task achievement), interpersonal (developing or maintaining a relationship), and identity (projecting a particular personal image). Reinsch and Turner (2019) proposed that the reason for multicommunicating is the achievement of communication objectives, and that these objectives would include instrumental, interpersonal, and identity goals.

Anecdotes included in previous studies make it clear that multicommunication is sometimes voluntary (that is, initiated by the focal person) and sometimes involuntary (e.g., one's supervisor insists that one 
attend a meeting and also exchange text messages with the supervisor). But the reasons for multicommunication have not been systematically investigated. We chose, therefore, to pose the following question:

\section{Q2: When they multicommunicate, what are students trying to achieve?}

\section{What Risks Do Students Perceive in Multicommunication?}

As noted, Reinsch and Turner (2019) argued (in their Proposition 1) that participation in multiple, overlapping interactions will be limited by a person's communication skills. That is, a person will stop adding additional interactions or withdraw from some current interactions if demands exceed his or her performance abilities.

While previous research has sometimes elicited descriptions of failed multicommunication episodes (e.g., Turner \& Reinsch, 2010), the risks perceived by multicommunicators have not been investigated. The perceptions of communicators may not always match reality (e.g., a person may misperceive his or her ability to juggle multiple interactions), but a communicator's perceptions would seem to be important factors in personal decision making. To better understand those perceptions, we asked the following question:

\section{Q3: Do students perceive multicommunicating as risky?}

\section{METHODS AND PROCEDURES}

We collected data at a small, private university in the southwestern United States, during a 17-day window near the end of the fall, 2020 semester. We used an on-line questionnaire (SurveyMonkey). The study was ruled "exempt" by the University's IRB. The questionnaire concerned student evaluations of their experiences with on-line education during the pandemic (data which are not included in the current paper) and their multicommunication behavior during the pandemic.

Some questions were answered on numerical, rating scales. Other questions were open-ended and required students to compose answers. (A portion of the questionnaire is included in the Appendix.)

We analyzed quantitative data using the Statistical Package for the Social Sciences (SPSS). We tested for potential statistical mediation using a four-step multiple-regression method (Frazier, Tix, \& Barron, 2004).

Open questions concerned reasons for multicommunicating and perceived risks while doing so ("things that could have gone wrong"). In order to analyze the answers, we used Tracy (2013) and Saldaña's (2012) method of inductive coding. The researchers read the responses multiple times, making notes and using invivo coding to identify concepts relevant to the research question. Concepts were identified as discrete answers to the question so that one response could conceivably contain multiple concepts. From this initial coding, a set of categories was identified. These categories were then compared to and integrated with the pre-existing categories and concepts from Reinsch and Turner (2019). All responses were then coded by the authors, working independently. When the authors disagreed, the issue was resolved through discussion. The results of this process were entered into a data spreadsheet and used in quantitative analysis.

\section{RESULTS}

We distributed the survey link to 1507 students. Partial responses were received from166 individuals (11\%). We discarded the scores from one respondent because the answers were internally inconsistent; we discarded scores from 11 respondents because their responses were fragmentary and could not be used to address any of the research questions. An additional 20 respondents were discarded because they did not answer questions related to multicommunication. This left a sample of 134 (9\% of the population) with some data missing. As shown in Table 1, the sample was 72 percent female and 29 percent male. These 
percentages differ from the student population (60\% female and $40 \%$ male) at a statistically significant level (Chi-square $=7.57 ; d f=1 ; \mathrm{p}<.01 ; C=.23)$.

\section{TABLE 1 \\ DESCRIPTIVE STATISTICS}

\begin{tabular}{|c|c|c|c|}
\hline Variable and Levels & $N$ & Mean & S.D. \\
\hline \multicolumn{4}{|l|}{ Sex } \\
\hline Male $(n=34)$ and No Response $(n=4)$ & $38(28 \%)$ & & \\
\hline Female & $96(72 \%)$ & & \\
\hline \multicolumn{4}{|l|}{ Academic Classification } \\
\hline \begin{tabular}{l|l} 
& Lower-division undergraduate \\
\end{tabular} & $52(39 \%)$ & & \\
\hline Upper-division undergraduate & $56(42 \%)$ & & \\
\hline Graduate & $26(19 \%)$ & & \\
\hline Frequency of Multicommunication (FoM) & 134 & 54.31 & 34.23 \\
\hline Change in Multicommunication (CiM) & 134 & 4.75 & 1.53 \\
\hline
\end{tabular}

On the other hand, the numbers of responses from various academic classification closely matched the profile of the population. There was a small group of "other" undergraduates (essentially "fifth-year seniors") so we grouped the undergraduates into two categories: Lower-division (first-year and second-year students) and upper-division (third-year and fourth-year students and "other").

\section{Did the Pandemic Encourage Multicommunicating? (Research Question \#1)}

Our first research question concerned the effects of the pandemic-related restrictions on the frequency of multicommunication (FoM). We focused on self-perceptions and the internal consistency of such perceptions.

We asked our respondents to rate their current level of multicommunication on a sliding scale from 0 ("I NEVER do this") to 100 ("I do this ALL the time"). As shown in Table 1, the mean rating of FoM was 54.31. (Fifteen persons responded with a 0 .)

To focus specifically on pandemic-induced changes we asked about them directly ("during the pandemic, have you increased or decreased the frequency" of multicommunicating?). For this variableChanges in Multicommunication (CiM) - we collected responses on a scale ranging from 1 (significant decrease) to 7 (significant increase). The mean response was 4.75. A 95 percent confidence interval around this sample mean ranged from 4.49 to 5.01 and did not include the midpoint (4.0) of the scale. We conclude, therefore, that students perceived their multicommunicating behavior as increasing during the pandemic.

In order to partially assess the internal consistency of the student self-perceptions, we also evaluated the relationship between student reports of CiM and their reports of current levels of FoM. The two scores were positively and significantly correlated $(r=.32, p<.01)$, indicating that those who perceived their multicommunicating behavior as having increased also reported higher levels of FoM.

To better understand factors that are related to FoM among students we used regression analysis to test for the effects of sex and academic classification, and the possibility that CiM might function as a mediator for the effects of sex and academic classification. Our sample was not large enough to allow us to use structural equation modeling (Frazier et al., 2004, p. 128). Consequently, we tested for mediation using a four-step multiple regression method (Frazier et al., 2004, p. 125) summarized in Figure 1. 
FIGURE 1

TESTING FOR MEDIATION

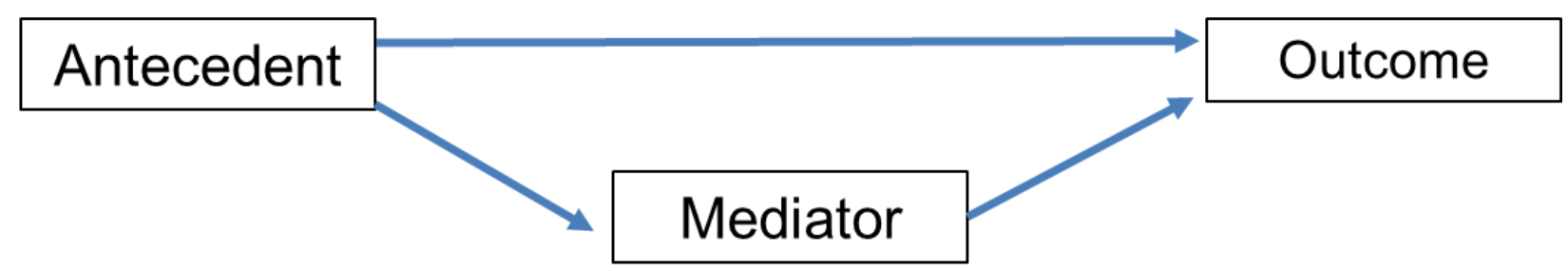

Step 1: Does the antecedent variable significantly predict the outcome variable?

Step 2: Does the antecedent variable significantly predict the potential mediator variable?

Step 3: Does the mediator variable significantly predict the outcome variable?

Step 4: When the mediator variable is used to predict the outcome variable, does the antecedent variable add to the explanatory power of the model?

As a first step (see Figure 1), we evaluated the impact of sex and academic classification on FoM. As shown by Model 1 (Table 2) both sex and academic classification (dummy coded) were statistically significant predictors FoM. Specifically, women described the frequency of their multicommunication as 60.06 (S.D. $=33.13$ ) on a 1-to100 point scale while men described the frequency of their multicommunication as 39.79 (S.D. $=33.03)$.

Academic classification also proved to have predictive value: Lower-division students reported the highest level of multicommunicating (mean $=64.75$; S.D. $=31.23$ ), while upper-division students reported a lower level $($ mean $=47.04$; S.D. $=34.63)$. Graduate students reported multicommunicating at an intermediate level $($ mean $=49.12$; S.D. $=35.09)$, but closer to the upper-division students than to the lowerdivision students. Together sex and academic classification accounted for approximately 13 percent of the variance in frequency of multicommunication.

To complete the second step of the process (Figure 1), we tested to see whether the same antecedent variables (sex and academic classification) were significant predictors of CiM. As shown by Model 2 (Table 2 ), academic classification was a significant predictor of change. Graduate students reported the greatest amount of change $($ mean $=5.12 ;$ S.D. $=1.45)$; lower-division students reported a somewhat smaller amount of change (mean =5.06; S.D. $=1.43$ ), and upper-division students reported the smallest amount of change $($ mean $=4.30 ;$ S.D. $=1.56)$. On the other hand, sex was not a significant predictor of CiM. While women reported a larger amount of change $($ mean $=4.84$; S.D. $=1.51)$ than did men $($ mean $=4.53$; S.D. $=1.57)$, the difference was not statistically significant. These findings rule out CiM as a mediator for the effects of sex.

TABLE 2

\section{REGRESSION ANALYSES: PREDICTING FREQUENCY AND CHANGE IN} MULTICOMMUNICATION

\begin{tabular}{|c|c|c|c|c|}
\hline Variables & B & Standard Error & Beta & $t$-score \\
\hline \multicolumn{5}{|c|}{ Model 1: Dependent Variable: Frequency of Multicommunication (FoM) } \\
\hline \multicolumn{5}{|c|}{$\mathrm{F}=7.53, \mathrm{df}=3 / 130 ; \mathrm{R}^{2}=.15 ;$ Adjusted $\mathrm{R}^{2}=.13$} \\
\hline Constant & 8.25 & 11.41 & & 0.72 \\
\hline Sex & 22.86 & 6.24 & 0.30 & $3.67 * *$ \\
\hline Academic Classification-D1 & 18.69 & 6.16 & 0.27 & $3.03 * *$ \\
\hline Academic Classification-D2 & -2.22 & 7.67 & -0.26 & -0.29 \\
\hline
\end{tabular}




\begin{tabular}{|c|c|c|c|c|}
\hline \multicolumn{5}{|c|}{ Model 2: Dependent Variable: Change in Multicommunication (CiM) } \\
\hline \multicolumn{5}{|c|}{$\mathrm{F}=3.26, \mathrm{df}=3 / 130 ; \mathrm{R}^{2}=.07 ;$ Adjusted $\mathrm{R}^{2}=.05$} \\
\hline Constant & 3.82 & 0.53 & & $7.17 * *$ \\
\hline Sex & 0.29 & 0.29 & 0.09 & 0.99 \\
\hline Academic Classification-D1 & 0.77 & 0.29 & 0.25 & $2.67 *$ \\
\hline Academic Classification-D2 & 0.76 & 0.26 & 0.20 & $2.12 *$ \\
\hline \multicolumn{5}{|c|}{ Model 3: Dependent Variable: Frequency of Multicommunication (FoM) } \\
\hline \multicolumn{5}{|c|}{$\mathrm{F}=14.68, \mathrm{df}=1 / 132 ; \mathrm{R}^{2}=.10 ;$ Adjusted $\mathrm{R}^{2}=.09$} \\
\hline Constant & 20.65 & 9.23 & & $2.24 *$ \\
\hline Change in Behavior & 7.08 & 1.85 & 0.32 & $3.83 * *$ \\
\hline \multicolumn{5}{|c|}{ Model 4: Dependent Variable: Frequency of Multicommunication (FoM) } \\
\hline \multicolumn{5}{|c|}{$\mathrm{F}=7.03, \mathrm{df}=3 / 130 ; \mathrm{R}^{2}=.14 ;$ Adjusted $\mathrm{R}^{2}=.12$} \\
\hline Constant & 18.94 & 9.16 & & $2.07 *$ \\
\hline Change in Behavior & 6.53 & 1.88 & 0.29 & $3.47 * *$ \\
\hline Academic Classification-D1 & 12.79 & 6.35 & 0.18 & $2.02 *$ \\
\hline Academic Classification-D2 & -3.22 & 7.77 & -0.04 & -0.41 \\
\hline \multicolumn{5}{|c|}{ Model 5: Dependent Variable: Frequency of Multicommunication (FoM) } \\
\hline \multicolumn{5}{|c|}{$\mathrm{F}=8.80, \mathrm{df}=4 / 129 ; \mathrm{R}^{2}=.21 ;$ Adjusted $\mathrm{R}^{2}=.19$} \\
\hline Constant & -14.57 & 12.99 & & -1.12 \\
\hline Change in Multicommunication & 5.98 & 1.81 & 0.27 & $3.30 * *$ \\
\hline Sex & 21.15 & 6.03 & 0.28 & $3.51 * *$ \\
\hline Academic Classification-D1 & 14.11 & 6.10 & 0.20 & $2.31 *$ \\
\hline Academic Classification-D2 & -6.76 & 7.52 & -0.08 & -0.90 \\
\hline
\end{tabular}

$* \mathrm{p}<.05 ; * * \mathrm{p}<.01$

The third step (Figure 1) is a test of the predictive power of the potential mediating variable. As previously noted, the CiM and FoM were significantly correlated, so it is no surprise to see (Model 3, Table 2) that CiM is a significant predictor of FoM, accounting for about nine percent of the variance.

The fourth step is to begin with the previously-developed predictive equation (Model 3, Table 2) and to test whether the antecedent variable makes a statistically significant addition to predictive power. (For example, if the effects of the antecedent variable are fully mediated, the antecedent variable will not enter the equation.) As shown by Model 4 (Table 2), academic classification (in the form of dummy variables) did enter the equation, increasing the variance explained (in comparison to Model 3) to approximately 12 percent. These results indicate that the effects of academic classification on FoM are partially mediated by $\mathrm{CiM}$. In other words, the statistical results indicate that academic classification has both direct and mediated (via CiM) effects on FoM among members of this population.

Then, to account for the maximum possible amount of variance, sex was added to the other variables to generate Model 5. As shown in Table 2, together the various antecedent and mediator variables account for approximately 19 percent of variance in FoM.

Thus, our data show that Sex and CiM have direct effects on FoM. In addition, academic classification has both a direct effect on FoM and (via CiM) an indirect effect. Together these effects explain about 19 percent of the variance.

\section{What Were Multicommunicating Students Trying to Achieve? (Research Question \#2)}

Our second research question concerned the goals of the respondents when multicommunicating. We asked them to recall a recent example and to explain "your reasons for participating." 
Ninety-nine respondents provided responses; 35 respondents did not. The group of 35 included the 15 who had previously identified themselves as persons who never engage in multicommunication.

Inductive coding (Saldaña, 2012; Tracy, 2013) yielded a number of specific, narrow categories involving work (e.g., "needed to respond to my boss while in class") or family relationships (e.g., "my mom texts me all the time in class") which were then grouped into instrumental, interpersonal, and identity goals (Clark \& Delia, 1979). Instrumental goals were defined as a focus on task completion (e.g., class assignments or workplace communications). Interpersonal goals were defined as a focus on managing a relationship, typically signaled by identifying the conversation partner as someone with a close personal relationship (e.g., spouse or children). Identity goals were defined as a desire to appear to be a certain sort of person (e.g., available and "connected," or not "rude").

The coders agreed $80 \%$ of time in judgments about instrumental goals, and $90 \%$ of the time in judgments about interpersonal and identity goals. Disagreements were resolved by discussion, yielding the results summarized in Table 3.

Seven responses were left unclassified. While a couple of the unclassified responses appeared to reflect a misunderstanding of the question, most were simply too cryptic to allow classification ("I was super busy and it was important," \#62; "It benefitted me," \#147).

Examination of Table 3 shows that instrumental goals were the most common. Forty-five responses were coded as having only instrumental goals and an additional 20 were coded has having an instrumental goal along with an additional goal. Thus, a total of 65 responses identified an instrumental goal as the reason, or one of the reasons, for multicommunicating.

The second most common type of goal was interpersonal, with a total of 39 responses. Twenty responses were coded as reflecting only an interpersonal goal; an additional 19 were coded as having an interpersonal goal along with another goal. The least common type of goal was identity, with a total of nine responses.

These results suggest that the framework proposed by Reinsch and Turner (2019) provides a good starting point for investigating personal decisions to multicommunicate. The results further suggest that university students during the Covid-19 pandemic engaged in multicommunication primarily for the purpose of getting work done-most often class assignments, or off-campus employment. (Incidentally, exploratory tests found no evidence that the sex of the respondent was related to the type of goal identified.)

TABLE 3

\section{REASONS FOR MULTICOMMUNICATING}

\begin{tabular}{|c|c|c|}
\hline Why Did You Multicommunicate? & Number & Percent \\
\hline Instrumental goal & 45 & $34 \%$ \\
\hline Interpersonal goal & 20 & $15 \%$ \\
\hline Identity goal & 6 & $4 \%$ \\
\hline Instrumental and Interpersonal goals & 18 & $13 \%$ \\
\hline Instrumental and Identity goals & 2 & $1 \%$ \\
\hline Interpersonal and Identity goals & 1 & $1 \%$ \\
\hline Unclassified & 7 & $5 \%$ \\
\hline No answer & 35 & $26 \%$ \\
\hline
\end{tabular}

\section{What Did Multicommunicating Students Risk? (Research Question \#3)}

The third research question focused on the risks of multicommunicating. We asked the students about "risks" and what "could have gone wrong" during a recent episode of multicommunication.

As summarized in Table 4, ninety students provided written responses; 44 did not. The group of 44 includes, once again, the 15 who described themselves as never multicommunicating. 
As before, we used the inductive coding process (Saldaña, 2012; Tracy, 2013). From the beginning of the coding, however, it was apparent that many of the answers were broad and vague rather than specific. For example, we had anticipated responses that could be coded as describing a number of specific communication skill missteps (e.g., sending a message to the wrong person, or being unprepared for a speaking turn). There were some comments of that sort, but not very many (and all of them are now grouped under "conversational management"). As a result, the set of categories that emerged included two sub-sets. One sub-set is essentially a negative image of the goals driving multicommunication (cf. Table 3). These categories describe responses that said, essentially, "what could have gone wrong was that I could have fallen short of my objectives." The other sub-set is concerned with communication failures broadly defined.

The coders agreed $90 \%$ of time in judgments about failure to achieve instrumental goals, $97 \%$ of the time in judgments about failure to achieve interpersonal goals, and $88 \%$ of the time in judgments about failure to achieve identity goals. They agreed $99 \%$ of the time in judgments about conversational management, and $84 \%$ of the time in judgments about generic miscommunication. They agreed $96 \%$ of the time about statements that multicommunicating presented few or no risks. As before, disagreements were resolved by discussion, yielding the results summarized in Table 4. Three responses were left unclassified.

We found most interesting the 31 responses that argued against the premise of the question-essentially claiming that nothing could go wrong. Many of these respondents simply wrote "no," or "none," or something equivalent. But others explained their reasoning in more detail. Some respondents pointed to their skill at multicommunicating ("No, I do good juggling," \#66; "No, I can multitask. I may have missed a couple of words, but I don't miss the main ideas," \#120). Others cited their skill at identifying messages which they could safely ignore ("I wouldn't have done this if actual instruction, that pertained to me, was happening," \#50; "It only occurred during certain classes that weren't needed to pay attention in," \#138). Some simply regarded the communication arena as one in which dangers were trivial ("Not really. It wasn't like I was driving." \#88). And one person reported that he had secured permission from one of the participants ("No, because I'd let [the] in-person friend know just a sec and will give full attention," \#51). Reflecting upon the answers which claimed there was little if any risk, provoked us to take a fresh look at the other answers: When students stated that they could have fallen short of a goal, were they referencing the normal vagaries of interpersonal communication, or were they acknowledging that multicommunication poses specific, heightened risks? We can't be sure. There were several answers that seemed to acknowledge specific challenges of multicommunicating (e.g., "I . . could've gotten confused as to who was who while I was texting, although that's never happened before," \#2; "Sometimes I would accidentally type [i.e., text] the response I wanted to say out loud to the person I'm talking with [face-to-face]," \#18). But manyperhaps as many as two-thirds - do not appear to be distinctive to multicommunication. We believe that some of our respondents now treat multicommunication as a normal, natural, and safe way of interacting. However, it would be a mistake to assume that all university students feel this way about multicommunicating. There were, as noted, several respondents who demonstrated a good understanding of the special challenges entailed and several who stated that they intentionally avoid such behavior.

\section{TABLE 4 \\ RISKS OF MULTICOMMUNICATING}

\begin{tabular}{|c|c|c|}
\hline What Could Have Gone Wrong? & Number & Percent \\
\hline \multicolumn{3}{|l|}{ Task Achievement Failure } \\
\hline Failure to Achieve Instrumental Goal & 1 & $1 \%$ \\
\hline Failures to Achieve Interpersonal Goal & 1 & $1 \%$ \\
\hline Failure to Achieve Identity Goal & 9 & $7 \%$ \\
\hline Failure to Achieve Instrumental and Identity Goals & 1 & $1 \%$ \\
\hline
\end{tabular}




\begin{tabular}{|c|c|c|}
\hline \multicolumn{3}{|l|}{ General Communication Failure } \\
\hline Conversation Management Failure & 4 & $3 \%$ \\
\hline Miscommunication & 30 & $22 \%$ \\
\hline Conversation Management Failure and Miscommunication & 3 & $2 \%$ \\
\hline \multicolumn{3}{|l|}{ Task Achievement Failure and Communication Failure } \\
\hline Failure to Achieve Instrumental Goal and Miscommunication & 4 & $3 \%$ \\
\hline Failure to Achieve Identity Goal and Miscommunication & 3 & $2 \%$ \\
\hline Low or no risk & 31 & $23 \%$ \\
\hline No Answer & 44 & $33 \%$ \\
\hline Unclassified & 3 & $2 \%$ \\
\hline
\end{tabular}

\section{DISCUSSION}

In this section of the paper, we note some limitations of the study. We then discuss the results before offering some comments about incorporating multicommunication into business classes.

\section{Limitations}

The study has limitations that are typical of many empirical studies. The data came from a single university at a specific time. And, in retrospect, it would have been helpful to request self-reports about the number of multicommunication episodes per day). More significantly and specifically, women responded at a significantly higher rate than did men. Differences in survey response rate by gender are relatively common (Curtin, Presser, \& Singer, 2000; Moore \& Tarnai, 2002; Singer, van Hoewyk, \& Maher, 2000) so we do not believe that there was something about our procedures that discouraged men from responding. On the other hand, it is important that the overall means from our sample not be taken as good estimates of behavior in the general population. In fact, given that our data show women to be more active multicommunicators than men, we believe that future studies should regularly include gender in their designs and evaluate the possibility of gender-specific effects.

\section{Meanings of the Results}

The results collected to address our first research question allow us to state that the respondents (both men and women) reported that FoM had increased during the pandemic and that they engaged in multicommunication somewhat frequently. The reports that the pandemic had resulted in increases, and the consistency between reported increases and reported levels of multicommunication, provide strong, albeit indirect evidence that the pandemic has increased the frequency with which college students engage in multicommunication.

A series of multiple regression analyses allow us to identify factors that appear to influence multicommunication behavior. One factor that had a direct effect was gender, with women reporting higher FoM than men. A number of studies have reported gender-related differences in communication behavior, though they tend to be small or moderate rather than large (Dindia \& Canary, 2010). More precise measurements of the differences in multicommunication, and the factors that produce them, would be an appropriate focus for future research.

Another factor that had both a direct and a mediated impact on FoM was academic classification. Among undergraduates, lower-division students reported more CiM and higher FoM than upper-division students. We assume that these differences reflect differences in maturation and life situation. Lowerdivision students are, in many cases, living away from home for the first time, still becoming acquainted with other students, enrolled in general-education courses, and developing new relationships. Upperdivision students have, in many cases, become at home on the university campus, have formed strong friendships, and spend a significant part of their time with other students who have chosen the same 
academic major. We suggest that such differences in circumstances result in different communication practices and differences in media use. Graduate students, on the other hand, reported the greatest amount of CiM. We believe this probably reflects the fact that many of the graduate students were working part- or full-time, and quite a number were married and had children. Their circumstances may have made multicommunication a particularly valuable addition to their communication repertoire during the pandemic.

As noted, CiM partially mediated the effects of academic classification. However, CiM also had its own effect. This reflects, we suspect, pandemic-related circumstances that affected students across all academic classifications. (In other words, we speculate that what appears to be a direct effect of CiM is, in fact, a mediated effect but one that involves antecedent variables - e.g., participation in on-line classesthat affected all of the surveyed students.)

The results of data collected to address our second and third research questions provide us with some direct insight into the decision processes of multicommunicators. The results suggest that university students multicommunicate for the same reasons that they communicate-they seek to achieve a variety of instrumental, interpersonal, and identity objectives. On the other hand, if they entertain thoughts about risks that multicommunicating may pose (and many of them appear to give little thought to such matters), they are most likely to consider the possibility of failing to achieve their objectives. And while many of the student comments do not reflect the levels of self-awareness that Reinsch and Turner assumed (especially with regard to risks), the results are consistent with Reinsch and Turner (2019). Indeed, one respondent (a first-year male) articulated his approach to multicommunication decisions in language that is closely parallel to the concepts articulated by Reinsch and Turner (2019). Respondent \#5 wrote:

Multitasking, in my opinion, is always ineffective. As such, I always run the risk of missing some important bit of information. I attempt to mitigate that risk by only doing it when I consider the benefit to outweigh the risk (e.g., communicating urgent information to my co-workers) or when the risk is reduced to nearly zero (e.g., there is a pause or lag in the class).

Incidentally, this respondent acknowledged that he had increased multicommunication during the pandemic $(\mathrm{CiM}=5)$ and now engaged in multicommunication $(\mathrm{FoM}=20)$.

The breakdown of findings attributing the reasons for multicommunicating provide insights into motivation. Past research found that task accomplishment drives many people to multicommunicate. However, by viewing multicommunicating as a type of multitasking, the human element of communication can be missed. It may be even easier to lose track of the human element when communication does not happen in a face-to-face, in-person setting. Previous research suggested that the compartmentalization or the lack of visual cues was a factor that contributed to multicommunicating. The present study reinforces this possibility.

\section{Suggestions for Pedagogy}

We believe that the practice of multicommunication has become sufficiently common that business courses should include the concept. In some courses, it may be appropriate to identify and experience specific forms of multicommunication or multicommunication management techniques (Gimenez, 2014). In other courses, a discussion of various concepts of social presence (Turner \& Foss, 2018; Turner, 2021) would be appropriate.

The current results also suggest to us a meso-level approach. Discussion of various types of conversational objectives - instrumental, interpersonal, and identity-would help student communicators to become more self-aware about their communication practices. Heightened self-awareness in the interpersonal arena can help student communicators to become more thoughtful about the risks that one accepts when multicommunicating. To offer one specific example that may resonate with students: When interviewing for a job, identity is a primary objective. One does not want to risk being perceived as unfocused, inattentive, or rude. An instructor can tell students "don't multicommunicate during a job 
interview." But a discussion of identity objectives and the risks posed by multicommunication can place that specific recommendation into a conceptual framework and encourage students to approach all of their interpersonal interactions thoughtfully (rather than relying on habits they have developed within a community of multicommunicating schoolmates).

\section{Suggestions for Practitioners and Managers}

Our results also have implications for business practitioners. The pandemic accelerated the migration to multicommunication, which was already under way (Reinsch \& Turner, 2019). We believe, consequently, that more frequent multicommunication will prove to be a permanent aspect of contemporary business life even as the pandemic fades. That means that business practitioners would benefit from a thoughtful approach to the practice.

When individuals multicommunicate, they are necessarily allocating part of their attention to one conversation and part of their attention to other conversations (Turner \& Reinsch, 2007) and in this way they are engaging in budgeted presence (Turner \& Foss, 2018). While budgeted presence might constitute an efficient use of their time, individuals need to be reflective about the long-term implications of practices that might create short-term efficiencies. Prioritizing instrumental objectives to the point of sacrificing interpersonal or identity objectives will not, in many cases, prove to be a wise approach.

Not only should individuals be thoughtful about their presence choices within conversations, teams and organizations need to be aware of conflicting pressures which require employees to be both fully present in meetings but also quick to respond to messages (Turner, 2021). Managers who have learned that their subordinates are adept at media use, may now expect subordinates to remain constantly available even as they return to a face-to-face environment and in-person work. Both managers and subordinates will need to carefully consider when such practices might be helpful, and when not.

Nor should managers overlook the modified preferences of their employees. Workers who have found that they prefer on-line meetings to long commutes and loafers to formal shoes (and clothing) may look for opportunities to zoom rather than to drive. The added flexibility in being able to balance the expectations of work and home might make the return to physical, in-person meetings suboptimal. Should organizations allow substitutions of zoom for face-to-face? At least part of the answer lies in careful assessment of the specific instrumental, interpersonal, and identity goals that an organization wants its employees to pursue. The pandemic has resulted in more options for hybrid work environments - that increases the need to reflect on communication practices. Our paper can help business practitioners to begin the needed reflection.

\section{CONCLUSION}

This study is more exploratory than definitive, as indicated by the use of research questions rather than hypotheses. It does, however, provide data that support the conceptual work of Reinsch and Turner (2019).

The study suggests that the Covid-19 pandemic has increased the frequency with which college students multicommunicate - a behavior change that, like some other behavioral changes, may outlast the pandemic (Sneader \& Singhkal, 2021). It also provides some of the most detailed information, to date, about the factors that influence individual decisions to multicommunicate.

\section{ACKNOWLEDGEMENT}

An earlier version of this paper was presented at the 2021 (March 18) meeting of the Association of Business Information Systems. 


\section{REFERENCES}

American Psychiatric Association. (n.d.). Workplace Mental Health-Working Remotely During COVID19. Center for Workplace Mental Health. Retrieved February 12, 2021, from http://www.workplacementalhealth.org/Employer-Resources/Working-Remotely-DuringCOVID-19

Cameron, A-F., \& Webster, J. (2011). Relational outcomes of multicommunicating: Integrating incivility and social exchange perspectives. Organization Science, 22, 754-771.

Clark, R.A., \& Delia, J.G. (1979). Topoi and rhetorical competence. Quarterly Journal of Speech, 65, 187-206.

Curtin, R., Presser, S., \& Singer, E. (2000). The effects of response rate changes on the index of consumer sentiment. Public Opinion Quarterly, 64, 413-428.

Dindia, K., \& Canary, D.J. (Eds.). (2010). Sex differences and similarities in communication (2nd ed.). New York, NY: Routledge.

Frazier, P.A., Tix, A.P., \& Barron, K.E. (2004). Testing moderator and mediator effects in counseling psychology research. Journal of Counseling Psychology, 51(1), 115-134.

Gimenez, J. (2014). Multi-communication and the Business English class: Research meets pedagogy. English for Specific Purposes, 35, 1-16.

Maruyama, T., \& Tietze, S. (2012). From anxiety to assurance: Concerns and outcomes of telework. Personnel Review, 41(4), 450-469. https://doi.org/10.1108/00483481211229375

Moore, D.L., \& Tarnai, J. (2002). Evaluating nonresponse error in mail surveys. In R.M. Groves, D.A. Dillman, J.L. Eltinge, \& R.J.A. Little (Eds.), Survey nonresponse (pp. 197-211). New York, NY: John Wiley \& Sons.

Nguyen, M.H., Gruber, J., Marler, W., Hunsaker, A., Fuchs, J., \& Hargittai, E. (in press). Staying connected while physically apart: Digital communication when face-to-face interactions are limited. New Media and Society.

Reinsch, N.L., Jr., \& Turner, J.W. (2019). Multicommunicator aspirational stress, suggestions for teaching and research, and other insights after 10 years of multicommunication research. Journal of Business and Technical Communication, 33, 141-171.

Reinsch, N.L., Jr., Turner, J.W., \& Tinsley, C.H. (2008). Multicommunicating: A practice whose time has come? Academy of Management Review, 33, 391-403.

Saldaña, J. (2012). The coding manual for qualitative researchers (2nd ed.). Thousand Oaks, CA: Sage Publishing.

Singer, E., van Hoewyk, J., \& Maher, M.P. (2000). Experiments with incentives in telephone surveys. Public Opinion Quarterly, 64, 171-188.

Sneader, K., \& Singhal, S. (2021, January) The next normal arrives: Trends that will define 2021-and beyond. New York, NY: McKinsey \& Company.

Stephens, K.K. (2012). Multiple conversations during organizational meetings: Development of the multicommunicating scale. Management Communication Quarterly, 26, 195-223.

Stephens, K.K., \& Davis, J. (2009). The social influences on electronic multi-tasking in organizational meetings. Management Communication Quarterly, 23, 63-83.

The Economist. (2020, November 24). People are working longer hours during the pandemic. Retrieved from https://www.economist.com/graphic-detail/2020/11/24/people-are-working-longer-hoursduring-the-pandemic

Tracy, S.J. (2013). Qualitative research methods: Collecting evidence, crafting analysis, communicating impact. Hoboken, NJ: Wiley-Blackwell.

Turner, J.W. (2020, April 14). Virtual communication can be tricky. What happens when every part of your life depends on it? Fast Company. Retrieved from https://www.fastcompany.com/90489915/virtual-communication-can-be-tricky-what-happenswhen-every-part-of-your-life-depends-on-it

Turner, J.W. (2021). Being present: Commanding attention at work and at home by managing your social presence. Washington, DC: Georgetown University Press. 
Turner, J.W., \& Foss, S.K. (2018). Options for the construction of attentional social presence in a digitally enhanced multicommunicative environment. Communication Theory, 28, 22-45.

Turner, J.W., \& Reinsch, N.L. (2007). The business communicator as presence allocator: Multicommunicating, equivocality, and status at work. Journal of Business Communication, 44(1), 36-59.

Turner, J.W., \& Reinsch, N.L., Jr. (2010). Successful and unsuccessful multicommunication episodes: Engaging in dialogue or juggling messages? Information Systems Frontiers, 12, 277-285.

Turner, J.W., Wang, F., \& Reinsch, N.L., Jr. (2020). How to be socially present when the class becomes "suddenly distant." Journal of Literacy and Technology, 21(2), 76-101.

Vanderkam, L. (2015, September 30). The science of when you need in-person communication. Fast Company. Retrieved from https://www.fastcompany.com/3051518/the-science-of-when-youneed-in-person-communication

Wallace, J.D., Burton, B.G., Chandler, R.C., \& Darby, D.G. (2020a). Providing foundations for an educational revolution: Moving towards an integrated perspective. Journal of Literacy and Technology, 21(2), 5-17.

Wallace, J.D., Burton, B.G., Chandler, R.C., \& Darby, D.G. (Eds.). (2020b). The elearning literacy for suddenly online - Considerations of theory, research, and practice [Special issues]. Journal of Literacy and Technology, 21(2\&3).

\section{APPENDIX: SELECTED QUESTIONNAIRE ITEMS}

6. During the current semester, how often do you find yourself "talking" (texting, emailing, telephoning, or speaking) to two or more different people at the same time? (Examples could include texting during a class period, texting with one friend while talking face-to-face with another friend, or any other occasion when you are juggling two or more communication interactions.) Please click on the dot and slide it to the correct point on the scale.

I NEVER do this 0
I do it ALL the time

7. Please think about a recent occasion when you were juggling two or more communication interactions (such as texting while participating in a class, either in person or on-line). On that occasion, what were your reasons for participating in more than one interaction at the same time? (Answer NA if this question does NOT APPLY to you because you never conduct two interactions at the same time.) [Text box for answer]

8. Thinking about the same occasion (as in Question 7), did juggling multiple interactions pose any risks for you? What are some things that could have gone wrong? (Answer NA if this question does NOT APPLY to you because you never conduct two interactions at the same time.) [Text box for answer]

9. During the pandemic, have you increased or decreased the frequency with which you participate simultaneously in two or more communication events?

_ Significant decrease (1)

_ Moderate decrease (2)

- Small decrease (3)

- No change (4)

- Small increase (5)

— Moderate increase (6)

_ Significant increase (7) 